\title{
Three-dimensional slope stability problem with a surcharge load
}

\author{
Y. M. Cheng ${ }^{1}$, N. Li ${ }^{1}$, and X. Q. Yang ${ }^{2}$ \\ ${ }^{1}$ Department of Civil and Environmental Engineering, Hong Kong Polytechnic University, Hong Kong, China \\ ${ }^{2}$ Building and Construction Department, Guangdong University of Technology, Guangzhou, China
}

Correspondence to: Y. M. Cheng (ceymchen@ polyu.edu.hk)

Received: 15 January 2015 - Published in Nat. Hazards Earth Syst. Sci. Discuss.: 11 February 2015

Revised: 31 August 2015 - Accepted: 3 September 2015 - Published: 8 October 2015

\begin{abstract}
A semi-analytical solution for the threedimensional stability analysis of the ultimate uniform patched load on top of a slope is developed by the limit analysis using kinematically admissible failure mechanisms. The failure mechanism which is assumed in the analytical solution is verified by three-dimensional strength reduction analyses and laboratory model test. Furthermore, the proposed method and the results are further compared with some published results for illustrating the applicability of the proposed failure mechanism.
\end{abstract}

\section{Introduction}

Many practical geotechnical problems are three-dimensional in nature, yet two-dimensional plane-strain analysis is commonly used for simplicity of analysis. This pertain to problems as natural slopes, cut slopes and fill slopes for which the failure regions usually have finite dimensions, and the actual problems are far from the plane strain condition. For twodimensional slope stability by the limit equilibrium method, the factor of safety is based on the equilibrium of discrete slices (Bishop, 1955; Morgenstern and Price, 1965; Spencer, 1967; Janbu, 1973). Two-dimensional analyses, though helpful for designing most of the slopes and embankments, are not applicable to slopes with local loads, which may lead to conservative design by assuming loads of an infinite extent through 2-D methods. Cheng et al. (2007) has demonstrated that the strength reduction method is similar to the limit equilibrium method in most cases, and the strength reduction method will also be adopted for comparisons in this study. Hong Kong has a long history of tragic landslides with significant loss of life and property damage. From government's record, more than 470 people died as a result of slope failures since 1947. Currently, the Hong Kong Government is spending about USD 130 million each year for slope stabilization, and such stabilization works have launched for about 40 years. More critical slope failure problems are being faced the Chinese Government, and there are various types of slope research underway in Hong Kong, China and many other areas. The present work is part of the continuous research programme by the authors (Cheng et al., 2013b; Li and Cheng, 2015), which include the use of innovative slope stabilization methods, debris flow flume and large-scale tests, advanced theory and design practice useful for both researchers and engineers, for both natural and reinforced slopes. Slopes in front of bridge abutment are very common in many countries. Currently, these slopes are commonly analyzed as twodimensional problems, and the present work is devoted to this problem with an aim of providing a more realistic tool (validated by experiments and numerical analysis) suitable for the engineers to use.

The common approach to analyze the three-dimensional slope stability problems is the three-dimensional limitequilibrium method which is the explicit extension of the corresponding two-dimensional methods (Hovland, 1977; Chen and Chameau, 1982; Azzouz and Baligh, 1983; Hungr, 1987; Lam and Fredlund, 1993; and Huang and Tsai, 2000, 2002). There are also several three-dimensional limit analysis models (Giger and Krizek, 1975; Michalowski, 1989; Chen et al., 2001a, b; Farzaneh and Askari, 2003) in literature. Michalowski (1989), Chen et al. (2001a, b) and Farzaneh and Askari (2003) have considered the three-dimensional problem by the limit analysis and the upper-bound theorem of plasticity, which are based on the three-dimensional models by Chen (1975). Cheng and Yip (2007) have proposed a three-dimensional limit equilibrium (LEM) slope stability model with explicit consideration of the sliding direction, 
and Wei et al. (2009) have carried out a detailed study about three-dimensional slope stability analysis using strength reduction method (SRM).

The safety factor for a three-dimensional problem is defined in the same way as for the corresponding twodimensional problems:

$c=c_{\mathrm{s}} / k$

$\tan \varphi=\tan \varphi_{\mathrm{s}} / k$

where $c_{\mathrm{s}}$ and $\varphi_{\mathrm{s}}$ are soil cohesion strength and internal friction angle, $k$ is the traditional safety factor, and $c$ and $\phi$ are the mobilized cohesive strength and internal friction angle, respectively. In most of the previous works based on the limit analysis, the failure mass is divided into several blocks with velocity discontinuity planes along the discontinuity surface and energy balance is applied (Chen, 1975).

Implementation of the upper bound theorem is generally carried out as follows. (a) First, a kinematically admissible velocity field is constructed. No separations or overlaps should occur anywhere in the soil mass. (b) Second, two rates are then calculated: the rate of internal energy dissipation along the slip surface and discontinuities that separate the various velocity regions, and the rate of work done by all the external forces, including gravity forces, surface tractions and pore water pressures. (c) Third, the above two rates are set to be equal. The resulting equation, called energy-work balance equation, is solved for the applied load on the soil mass. This load would be equal to or greater than the true collapse load (Cheng and Lau, 2013).

It should be mentioned that discontinuous fields of velocity is used in applying upper bound theorem. Surfaces of velocity discontinuity are clearly possible, provided the energy dissipation is properly computed. For instance, rigid-body sliding of one part of the body against the other part is a well-known example. This discontinuous surface should be regarded as the limiting case of continuous velocity fields, in which one or more velocity components change very rapidly across a narrow transition layer, which is replaced by a discontinuity surface as a matter of convenience. Discontinuous velocity fields not only prove convenient but often are contained in actual collapse mode or mechanism (Chen and Liu, 1990).

This approach is acceptable for a two-dimensional analysis, but a realistic three-dimensional failure mechanism should have a radial shear zone which is difficult to be modelled by wedges. Chen et al. (2003) overcome this limitation by the use of many small rigid elements and nonlinear programming technique for the minimization analysis, but this method requires very long computer time in the optimization process, and the location of the global minimum is not easily achieved.

In this paper, semi-analytical solutions for a patched uniform distributed load acting on or below the top surface of a slope are developed. This problem can also be viewed as a bearing capacity problem as well as a slope stability problem. The failure mechanism presented in this study is a more reasonable mechanism based on the kinematically admissible approach of a typical bearing capacity problem. It is a further development of the works based on some of the above researches by using a more reasonable three-dimensional radial shear failure zone through which other three-dimensional failure wedges are connected together with, and a solution can be obtained within very short time as the semi-analytical expressions are available. The present solutions have given good results when compared with some previous studies and a laboratory test shown in Fig. 6, also demonstrated by Li and Cheng (2015). The laboratory test has also revealed some interesting progressive failure phenomenon and deformation characteristic for this slope failure problem.

\section{Theoretical background of the 3-D failure mechanism}

Kinematically admissible velocity fields used in the upper bounds analysis usually have a distinct physical interpretation which is associated with the true collapse mechanisms known from experiments and practical experience. The present failure mechanism complies with the requirements in limit analysis and is similar to that as found from laboratory tests which will be illustrated in a later section. Stress fields used in the lower-bound approach, however, are constructed without a clear relation to the real stress fields, other than the stress boundary conditions. Moreover, most problems involve a semi-infinite half-space, and the extension of the stress field into the half-space is either cumbersome or appears to be impossible (Michalowski, 1989). For general three-dimensional problems, the construction of an admissible stress field is very difficult, and only very few cases are successfully solved by the lower bound approach. As a result, only the upper-bound kinematical admissible approach is commonly adopted for solving such problems.

As demonstrated by Cheng et al. (2013a), under the action of self-weight, the classical log-spiral zone is no longer a rigorous solution to the failure mechanism. For a ground with a certain incline, the authors have tried the slip-line analysis and have found that the classical log-spiral and wedge failure mechanism will enclose the slip-line solution (but very close), which means that the volume of failure mass from plasticity formulation is only slightly less than that from the classical formulation using log-spiral curve. The middle part of the failure mechanism is mainly controlled by the patch load, and the failure mechanism which is now asymmetric due to the slope in front of the patch load can be represented by the typical solutions from slip solution which have been given by Cheng and $\mathrm{Au}$ (2005) and Cheng et al. (2013a). For the transition zone outside the patch load edge, as the soil is moving sideways, a lateral wedge, log-spiral zone and wedge failure mechanism can be constructed which will gradually 
merge with the ground surface. This lateral failure mechanism can be viewed as the effect of the Poisson's ratio which generate lateral stress and hence lateral failure. The details and the geometry of the failure mechanism will be discussed in details in the following sections.

\section{Three-dimensional slope failure of a slope with patched load on the top surface $(D=0 \mathrm{~m})$}

A simple three-dimensional slope failure mechanism with zero embedment depth patch load $(D=0 \mathrm{~m})$ is shown in Fig. 1. The failure mechanism is asymmetric as there is slope in front of the patch load, and the failure mechanism is controlled by angle $\zeta$ and $\xi$ which are to be determined. The surface between the footing and the soil is assumed to be smooth in the present study. Figure $1 \mathrm{~b}$ is the failure mechanism at the section through the applied load, while the end effects are shown in Fig. 1c, which is the failure zone normal to the section in Fig. $1 \mathrm{~b}$ and illustrated as $a g g$ ' zone on the left and right sides of Fig. 1d. The bird view of the threedimensional failure mechanism is shown in Fig. 1d. The total works done are calculated as below.

\subsection{Rate of work done produced along load length $L$}

In the following analysis, some of the geometry determinations are given in the Appendix while the main theme about the energy balance will be discussed. Based on Fig. 1b, the resistance rate of work done $P$ dissipated by the cohesion $c$ along the velocity discontinuity plane $a c \cdot L$ is given as

$P_{\mathrm{R} 1}=c \cdot a c \cdot L \cdot v_{0} \cos \varphi$,

where $a c=B \sin \xi / \sin (\zeta+\xi)$ and $r_{0}=b c=B \sin \zeta / \sin (\zeta+$ $\xi), B$ is the width of the footing and $L$ is the length of the footing normal to the section as shown in Fig. 1b but excluding the two end effects. Resistance rate of work done dissipated in the radial shear zone bcd is written as (see Chen, 1975)

$P_{\mathrm{R} 2}=c v_{0} r_{0} L \frac{\exp (2 \Theta \tan \varphi)-1}{\tan \varphi}$.

Resistance rate of work done dissipated by cohesion $c$ along the velocity discontinuity plane $d g \cdot L$ is given by

$P_{\mathrm{R} 3}=c \cdot d g \cdot L \cdot v_{3} \cos \varphi$,

in which $v_{3}=v_{0} \exp (\Theta \tan \varphi)$, and $b d=r_{0} \exp (\Theta \tan \varphi)$.

As shown in Fig. 1b, point $b$ is taken as the reference point $(0,0,0)$ of the coordinates axes, and positive directions are pointing left and downward. The rate of work done produced by the external pressure $q$ on the top of the slope is expressed as

$P_{\mathrm{D} 1}=q B L v_{1}$.
The rate of work done produced by the weight of the wedge $a b c$ is written as

$P_{\mathrm{D} 2}=W_{a b c} v_{0} \sin (\zeta-\varphi)$

where $W_{a b c}=\frac{\gamma}{2} a c \cdot B \cdot L \sin \zeta$. The rate of work done produced by the weight of the radial shear zone $b c d$ is given as (see Chen, 1975)

$$
\begin{aligned}
& P_{\mathrm{D} 3}=\frac{\gamma}{2} \int_{0}^{\Theta} r^{2} L v \cos (\theta+\xi) d \theta \\
& =\frac{\gamma}{2} r_{0}^{2} L v_{0} \\
& \frac{\exp (3 \Theta \tan \varphi)[\sin (\Theta+\xi)+3 \tan \varphi \cos (\Theta+\xi)]-\sin \xi-3 \tan \varphi \cos \xi}{1+9 \tan ^{2} \varphi}
\end{aligned}
$$

The rate of work done dissipated by the weight of the wedge $b d g i$ is formulated as (refer to Eq. (A1)-(A4) of Appendix)

$P_{\mathrm{D} 4}=W_{b d g i} \cdot v_{3} \cos \left(180^{\circ}-\eta\right)$
$W_{b d g i}=\gamma L\left(S_{b i g}+S_{b d g}\right)$.

\subsection{Rate of work done produced at the two end-failure zones of the footing}

A lateral wedge, log-spiral, wedge failure mechanism has been assumed in the present study, and the rate of work done will be considered here. The overall results based on the present mechanism are found to be better than some other published results which will be shown later.

1. End failure zone 1 (correspond to side of failure below foundation at mid-section, illustrated as plane $a c c^{\prime}$ in Fig. 1c)

As shown in Fig. 1c, $c c^{\prime}$ is a horizontal line normal to the plane $a b c$. In order to ensure that the sliding velocity of the soil mass of the end-failure zone 1 is equal to $v_{0}$, the angle between $a c$ and should be equal to $\phi$, therefore, $c c^{\prime}=r_{0} \tan \varphi, r_{0}=a c$ (refer to Eq. (A5) of the Appendix). The rate of work done by the velocity discontinuity plane $a c c^{\prime}$ is then expressed as

$P_{\mathrm{RE} 1}=c \cdot S_{a c c^{\prime}} \cdot v_{0} \cos \varphi$,

where $S_{a c c^{\prime}}=\frac{1}{2} a c \cdot c c^{\prime}$. The rate of work done produced by the weight of the wedge $a b c-c^{\prime}$ is expressed as

$P_{\mathrm{DE} 1}=W_{a b c-c^{\prime}} \cdot v_{0} \sin (\zeta-\varphi)$.

2. End failure zone 2 (correspond to the log-spiral zone at mid-section, illustrated as plane $c c^{\prime} d$ 'd in Fig. 1c, and the geometry should be referred to Eqs. (A6)-(A7) of the Appendix) 


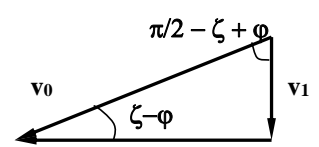

(a) velocity diagram for wedge abc

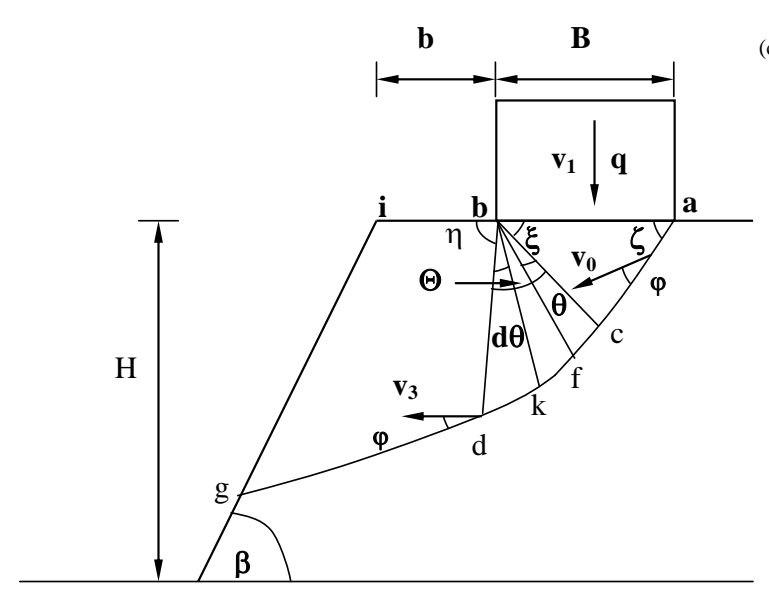

(b) failure mechanism (excluding the two ends)

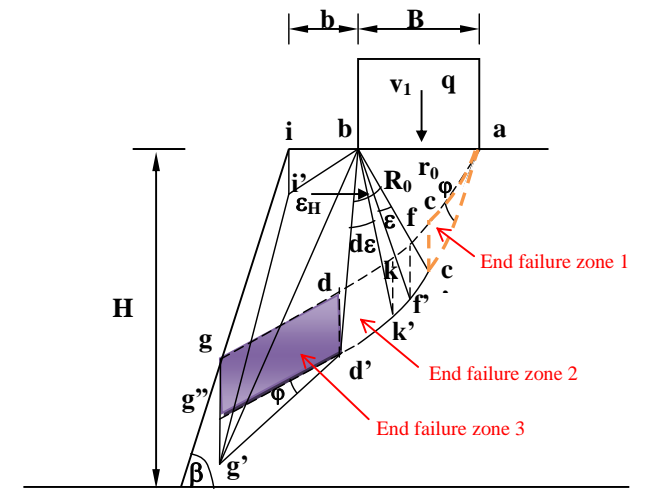

(c) failure mechanism of section AA for the two ends aig and agg'

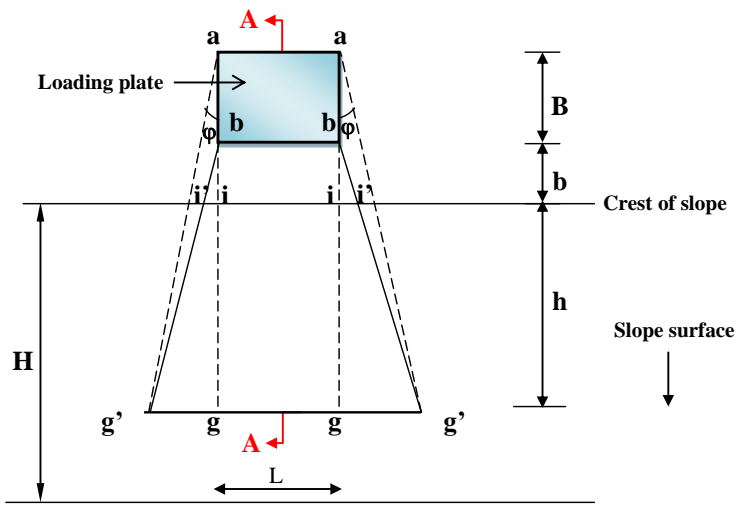

(d) three-dimensional failure mechanism on plan

Figure 1. Three-dimensional failure mechanism for slope problem with a patch load.

a. Velocity discontinuity curve plane $b c^{\prime} d^{\prime}$ (refer to Eq. (A8) of the Appendix)

The resistance rate of work done produced by $c$ along the velocity discontinuity plane $b c^{\prime} d^{\prime}$ is integrated as

$$
\begin{gathered}
P_{\mathrm{RE} 2}=\int_{0}^{\varepsilon_{H}} c \cdot S_{b f^{\prime} k^{\prime}} \cdot v \cos \varphi \cdot d \theta=\frac{1}{2} c v_{0} R_{0}^{2} \\
\quad \cos \varphi \int_{0}^{\Theta} \exp (3 \theta \tan \varphi) d \theta \\
=\frac{\cos \varphi}{6 \tan \varphi} c v_{0} R_{0}^{2}[\exp (3 \Theta \tan \varphi)-1]
\end{gathered}
$$

b. Velocity discontinuity plane $c c^{\prime} d^{\prime} d$ (refer to Eqs. (A9)- (A10) of the Appendix)

The resistance rate of work done produced by the velocity discontinuity area $c c^{\prime} d^{\prime} d$ is obtained as

$$
\begin{aligned}
P_{\mathrm{RE} 3} & =\int_{0}^{\Theta} S_{f f^{\prime} k^{\prime} k} \cdot v \cdot c \cos \varphi d \theta \\
& =\frac{1}{3} r_{0}^{2} v_{0} c[\exp (3 \Theta \tan \varphi)-1]
\end{aligned}
$$

c. Radial shear zone $b-c c^{\prime} d^{\prime} d$ (refer to Eq. (A11) of the Appendix)

Dissipated rate of work done produced in the radial zone is given as

$$
\begin{gathered}
P_{\mathrm{RE} 4}=\int_{0}^{\Theta} S_{b f f^{\prime}} \cdot c \cdot v d \theta=\frac{1}{2} r_{0}^{2} c v_{0} \\
\tan \varphi \int_{0}^{\Theta} \exp (3 \theta \tan \varphi) d \theta \\
=\frac{1}{6} r_{0}^{2} c v_{0}[\exp (3 \Theta \tan \varphi)-1]
\end{gathered}
$$


d. Weight of the radial zone $b-c c^{\prime} d^{\prime} d(0 \leq \theta \leq \Theta)$ (refer to Eq. (A12) of the Appendix)

The driving rate of work done produced by the weight of the wedge is expressed as

$$
\begin{aligned}
& P_{\mathrm{DE} 2}=\int_{0}^{\Theta} W_{b-f f^{\prime} k^{\prime} k} \cdot v \cos (\xi+\theta) d \theta \\
& =\frac{\gamma}{3} r_{0}^{2} R_{0} v_{0} \sin \varphi \\
& \frac{\exp [4 \Theta \tan \varphi][\sin (\Theta+\xi)+4 \tan \varphi \cos (\Theta+\xi)]-\sin \xi-4 \tan \varphi \cos \xi}{1+16 \tan ^{2} \varphi}
\end{aligned}
$$

3. End failure zone 3 (correspond to the wedge zone outside the log-spiral zone, illustrated as plane $d d^{\prime} g$ " $g$ in Fig. 1c)

a. Resistance rate of work done produced by $c$ along the velocity discontinuity plane is then obtained as (refer to Eq. (A13) of the Appendix)

$P_{\mathrm{RE} 5}=c \cdot S_{d d^{\prime} g^{\prime} g} \cdot v_{3} \cos \varphi$.

b. Velocity discontinuity plane $b d^{\prime} g^{\prime} i^{\prime}$ (refer to Eqs. (A14)-(A17) of the Appendix)

The resistance rate of work done produced by $c$ along the velocity discontinuity plane is written as

$P_{\mathrm{RE} 6}=c \cdot\left(S_{b d^{\prime} g^{\prime}}+S_{b g^{\prime} i^{\prime}}\right) \cdot v_{3} \cos \varphi$

c. Wedge $b-d d^{\prime} g^{\prime} g$

Weight of the wedge $b-d d^{\prime} g^{\prime} g$ is expressed as

$W_{b-d d^{\prime} g^{\prime} g}=\frac{\gamma}{3} S_{d d^{\prime} g^{\prime} g} \cdot b d \cos \varphi$.

. The corresponding resistance rate of work done produced by the weight of wedge is obtained as

$P_{\mathrm{DE} 3}=W_{b-d d^{\prime} g^{\prime} g} \cdot v_{3} \cos \left(180^{\circ}-\eta\right)$

d. Wedge $b-g g^{\prime} i^{\prime} i$

Weight of the wedge $b-g g^{\prime} i^{\prime} i$ is given by

$W_{b-g g^{\prime} i^{\prime} i}=\frac{\gamma}{3} \cdot S_{g g^{\prime} i^{\prime} i} \cdot b \sin \beta$.

in $\quad$ which $\quad S_{g g^{\prime} i^{\prime} i}=\frac{1}{2} g i \cdot\left(y_{i^{\prime}}+y_{g^{\prime}}\right), \quad g i=$ $\sqrt{\left(x_{g}-x_{i}\right)^{2}+\left(z_{g}-z_{i}\right)^{2}}$.

Then resistance rate of work done produced by the weight of the wedge is

$P_{\mathrm{DE} 4}=W_{b-g g^{\prime} i^{\prime} i} \cdot v_{3} \cos \left(180^{\circ}-\eta\right)$.
The total resistance rate of work done of the failure mechanism shown in Fig. 1 is expressed as

$$
\begin{aligned}
& P_{\mathrm{R}}=P_{\mathrm{R} 1}+P_{\mathrm{R} 2}+P_{\mathrm{R} 3}+2\left(P_{\mathrm{RE} 1}+P_{\mathrm{RE} 2}\right. \\
& \left.+P_{\mathrm{RE} 3}+P_{\mathrm{RE} 4}+P_{\mathrm{RE} 5}+P_{\mathrm{RE} 6}\right) .
\end{aligned}
$$

The total driving rate of work done is obtained as

$$
\begin{aligned}
& P_{\mathrm{D}}=P_{\mathrm{D} 1}+P_{\mathrm{D} 2}+P_{\mathrm{D} 3}+P_{\mathrm{D} 4}+2\left(P_{\mathrm{DE} 1}\right. \\
& \left.+P_{\mathrm{DE} 2}+P_{\mathrm{DE} 3}+P_{\mathrm{DE} 4}\right) .
\end{aligned}
$$

By means of Eqs. (1) and (2), the safety factor $k$ are obtained by means of a simple looping method starting as $k=1.0$ in the initial trial then trying with different $k$ until the following equation is satisfied:

$P_{\mathrm{R}}-P_{\mathrm{D}}=f(\zeta, \xi, \eta)=0$,

where the angles $\zeta, \xi$ and $\eta$ related to the $k$ value are the critical failure angles, $\zeta_{\mathrm{cr}}, \xi_{\mathrm{cr}}$ and $\eta_{\mathrm{cr}} ; f$ is a yield function and plastic flow can occur only when the yield function is equal to 0 (Chen and Liu, 1990). Various techniques can be used to solve Eq. (25) for which there are four variables ( 3 angles plus $k$ ). Instead of using advanced numerical technique for this problem, the authors have chosen to use a very simple looping method. Each variable is looped within a specified and acceptable range, and the rate of increment of the angle is generally kept to be $0.5^{\circ}$ initially. During the solution of nonlinear Eq. (25), it is found that the solution is very sensitive to the parameters near to the critical solution. A small change of even $0.5^{\circ}$ can sometimes have a noticeable effect to the solution of Eq. (25) under such condition. Regarding that, a small interval of $0.2^{\circ}$ is chosen in the present study. The advantage of the looping technique is that the sensitivity of the solution algorithm can be avoided simply by a small interval of $0.2^{\circ}$ instead of using special treatment in the numerical algorithm. Even with such a small interval in the search for the critical solution, the solution time is extremely fast and is acceptable.

\section{Three-dimensional slope failure with an embedded patched load $(D>0 \mathrm{~m})$}

General three-dimensional slope failure with an embedded patch load with $D>0 \mathrm{~m}$ is shown in Fig. 2. The failure mechanism is actually very similar to the case of $D=0$ in the previous section, with only minor change in the geometry calculation (see also Appendix). The rates of work done for various components are formulated as below. 


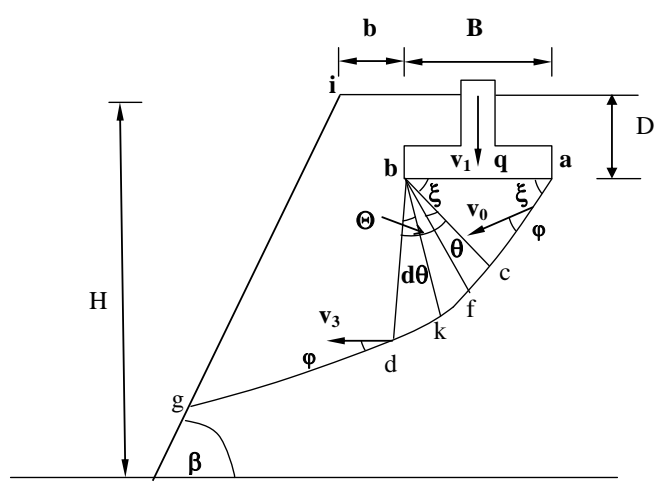

(a) failure mechanism (excluding the two ends)

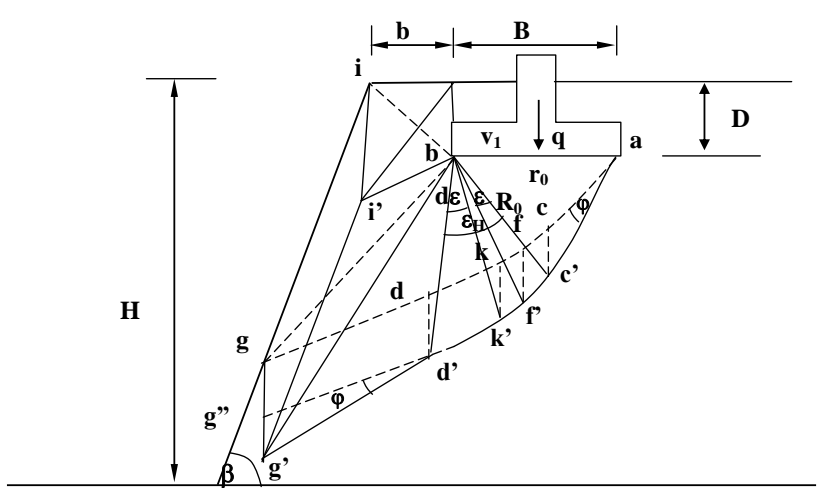

(b) failure mechanism for the two ends

Figure 2. Three-dimensional failure mechanism for slope with buried patch load.

\subsection{Rate of work done produced along footing length $L$}

- Resistance rate of work done dissipated by cohesion $c$ along velocity discontinuity plane $d g \cdot L$ is calculated by (refer to Eqs. (A18)-(A20) of the Appendix)

$$
P_{\mathrm{R} 3}=c \cdot d g \cdot L \cdot v_{3} \cos \varphi
$$

in which $\quad v_{3}=v_{0} \exp (\Theta \tan \varphi), \quad$ and $\quad b d=$ $r_{0} \exp (\Theta \tan \varphi)$.

- Resistance rate of work done is produced by the weight of the wedge bdgih (refer to Eq. (A21a)-(c) of the Appendix):

$$
W_{b d g i h}=\gamma \cdot L \cdot S_{b d g i h}
$$

Then, the rate of work done produced by the weight of the wedge bdgih is given as (refer to Eqs. (A23)-(A25) of the Appendix)

$$
P_{\mathrm{D} 4}=W_{b d g i h} \cdot v_{3} \cos \left(180^{\circ}-\eta\right),
$$

Other items such as $P_{\mathrm{R} 1}, P_{\mathrm{R} 2}$ and $P_{\mathrm{D} 1} \sim P_{\mathrm{D} 3}$ are similar to those given in the previous section and will not be repeated here.

\subsection{Rate of work done produced at two failure ends of the buried load}

a. Velocity discontinuity plane $b d^{\prime} g^{\prime} i^{\prime}$ (refer to Eqs. (A22)-(A26), Eq. (A27) of the Appendix)

For the velocity discontinuity plane $b d^{\prime} g^{\prime}$, it is similar to the previous case except that

$$
b i^{\prime}=\sqrt{x_{i^{\prime}}^{2}+y_{i^{\prime}}^{2}+z_{i^{\prime}}^{2}}
$$

The resistance rate of work done produced by $c$ along the velocity discontinuity plane $b d^{\prime} g^{\prime} i^{\prime}$ is also given by Eq. (18).

b. Resistance rate of work done produced by the tensile failure plane $b h i^{\prime}$

Area of the tensile failure plane $b h i^{\prime}$ is expressed as

$S_{b h i^{\prime}}=\frac{1}{2} D \cdot h i^{\prime}$

in which $h i^{\prime}=\sqrt{b^{2}+y_{i^{\prime}}^{2}}$. Usually, the tensile strength of soil mass can be taken as (1/4-1.0)c (Baker, 1981; Bagge, 1985). Calculation as shown in later part of this paper will demonstrate that the tensile strength of soil mass has only a small effect on the safety factor, so it is assumed to be equal to $c / 3$ in the present study (any other value can be obtained easily by a very simple modification of Eq. 31). As the tensile direction is along the direction of velocity $v_{3}$, the corresponding resistance rate of work done produced by the tensile failure plane is written as

$$
P_{\mathrm{RE7}}=c \cdot S_{b h i^{\prime}} \cdot v_{3} / 3
$$

c. Driving rate of work done produced by wedges $b-$ $d d^{\prime} g^{\prime} g, b-i i^{\prime} g^{\prime} g$ and $b-h i i^{\prime}$

Then driving rate of work done produced by the weight of these wedges is expressed as

$$
\begin{aligned}
P_{\mathrm{DE} 3}= & \left(W_{b-d d^{\prime} g^{\prime} g i}+W_{b-i i^{\prime} g^{\prime} g}+W_{b-h i i^{\prime}}\right) \\
& \cdot v_{3} \cos \left(180^{\circ}-\eta\right) .
\end{aligned}
$$


Other items $W_{\mathrm{RE} 1} \bullet^{\bullet} \sim W_{\mathrm{RE} 5} \bullet^{\bullet}$ and $W_{\mathrm{DE} 1} \bullet^{\bullet} \sim W_{\mathrm{DE} 2}{ }^{\bullet}$ are similar to the case for $D=0 \mathrm{~m}$ and will not be repeated here. Referring to Fig. 2, the total resistance rate of work done is expressed as

$$
\begin{aligned}
P_{\mathrm{R}}= & P_{\mathrm{R} 1}+P_{\mathrm{R} 2}+P_{\mathrm{R} 3}+2\left(P_{\mathrm{RE} 1}+P_{\mathrm{RE} 2}\right. \\
& \left.+P_{\mathrm{RE} 3}+P_{\mathrm{RE} 4}+P_{\mathrm{RE} 5}+P_{\mathrm{RE} 6}+P_{\mathrm{RE} 7}\right) .
\end{aligned}
$$

The total driving rate of work done of Fig. 2 is obtained as

$$
\begin{aligned}
P_{\mathrm{D}} & =P_{\mathrm{D} 1}+P_{\mathrm{D} 2}+P_{\mathrm{D} 3}+P_{\mathrm{D} 4} \\
& +2\left(P_{\mathrm{DE} 1}+P_{\mathrm{DE} 2}+P_{\mathrm{DE} 3}\right) .
\end{aligned}
$$

$k$ will be obtained by setting Eq. (33) equals Eq. (34).

\section{Comparison of the authors' method with other analytical solutions}

Referring to Fig. 1 , when $b=0$, based on the well-known slip-line solutions by Sokolovskii (1960), the closed form solution of bearing capacity factor $N_{\mathrm{c}}$ to the ultimate bearing pressure $q_{\mathrm{u}}\left(q_{\mathrm{u}}=c N_{c}+q N_{q}\right)$ for a weightless soil mass is given by

$N_{\mathrm{c}}=c \cdot \cot \varphi\left\{\tan ^{2}\left(45^{\circ}+\frac{\varphi}{2}\right) \exp [(\pi-2 \beta) \tan \varphi]-1\right\}$.

For a two-dimensional plane problem with weightless soil mass, $N_{\mathrm{c}}$ values for different slope angles are calculated by using Eq. (25). Safety factor $k$ is set to 1.0, and an arbitrary value of $c$ (10 kPa used by the author) is used in Eq. (25) for a given $\varphi$. The value of $q_{\mathrm{u}}$ is adjusted by trial and error until Eq. (25) is satisfied. Since $q$ which is the surcharge outside the foundation is $0, N_{\mathrm{c}}$ is hence determined. The same result can also be determined Eq. (35), and the results are shown in Fig 3. The general trends for the variations of the $N_{\mathrm{c}}$ and angle friction, which was predicted by both of the methods, are similar, but $N_{\mathrm{c}}$ values by Eq. (25) are only slightly larger than the $N_{\mathrm{c}}$ values by Eq. (35). This indicates that the threedimensional failure mechanism of Fig. 1 is a reasonable upper bound solution for two-dimensional analysis.

Further comparison has been carried out for a threedimensional slope stability analyses with the following soil properties $\left(c=20 \mathrm{kN} \mathrm{m}^{-2}, \varphi=20^{\circ}\right.$ and $\left.\gamma=20 \mathrm{kN} \mathrm{m}^{-3}\right)$ and slope geometry ( $B=2 \mathrm{~m}, b=1 \mathrm{~m}, D=0 \mathrm{~m}$ and $H=6 \mathrm{~m})$. The results of the dimensionless limit pressure $q_{\mathrm{u}} / c$ values with different $L / B$ values are illustrated in Fig. 4 , and the results by the authors are slightly smaller than those by Michalowski (1989). According to the upper bound theorem, the smaller result obtained by the authors will be the better result. Since both the present approach and the one by Michalowski (1989) are upper bound approach with only minor differences in the failure mechanism, slightly smaller results by the authors imply the failure mechanism as adopted

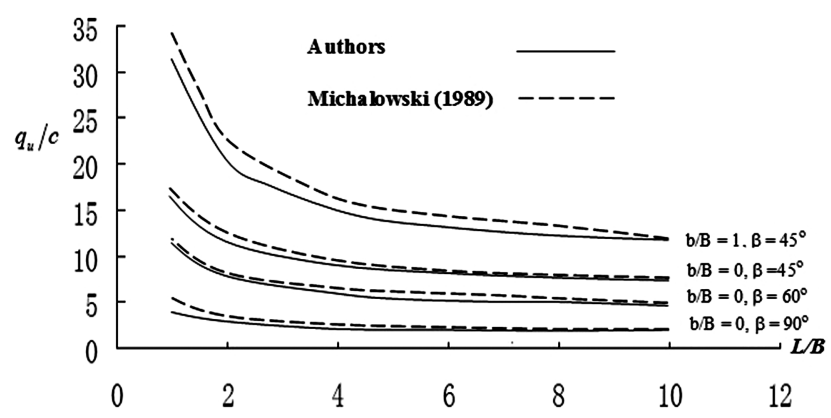

Figure 3. Comparison of present results with upper-bound solutions by Michalowski (1989).

is closer to the true failure mechanism. The ultimate pressures decrease with the increase in $L / B$ ratio. Until the $L / B$ value greater than 5 , the normalized ultimate pressures are not sensitive to the variations of the $L / B$ values. Such trends are shown in both of the methods. This indicates that the effect of the patched pressure on the top surface of the slope will increases rapidly as the dimension $L / B$ ratio is reduced, especially for $L / B<5$. Moreover, the ultimate pressures given by the authors are slightly lower than the ultimate pressure given by Michalowski (1989), which required more parameters in the formulations. According to the upper bound theorem in plasticity (Chen, 1975), the present three-dimensional failure modes are more reasonable and more critical than that by Michalowski (1989), as the ultimate pressure from the present formulation is smaller than that by Michalowski (1989). Compared with other previous works, the present results can give better predictions for the ultimate local pressure on the top surface of the slope.

As mentioned previously, the tensile strength of soil has very little impact on the results of analysis. The authors have tried to change the tensile strength equal to $1 / 3 c$ to $1 / 2 c$ in the analysis and have found that the results in Fig. 3 are nearly not affected, particularly when $\beta$ is small (below $30^{\circ}$ ). When $\beta$ is large, the changes in the results are limited to less than $3 \%$ in general. Regarding of that, the results in Fig. 3 can be used directly in general without any practical needs for refinement.

\section{Verification by numerical analysis}

To verify the authors' analytical formulations, a series of numerical analyses are carried out. FLAC3D finite difference package is adopted for the three-dimensional strength reduction method (SRM). In example 1, the soil properties parameters are $c=20 \mathrm{kN} \mathrm{m}^{-2}, \phi=20^{\circ}$ and $\gamma=20 \mathrm{kN} \mathrm{m}^{-3}$ while the geometry are given by $B=2 \mathrm{~m}, b=1 \mathrm{~m}, D=0 \mathrm{~m}$, $H=6.0 \mathrm{~m}$ and $\beta=45^{\circ}$. The safety factors evaluated from the authors' analytical solution and the numerical analyses are shown in Table 1. The maximum difference between both results is less than $10 \%$. Both methods predicted that 


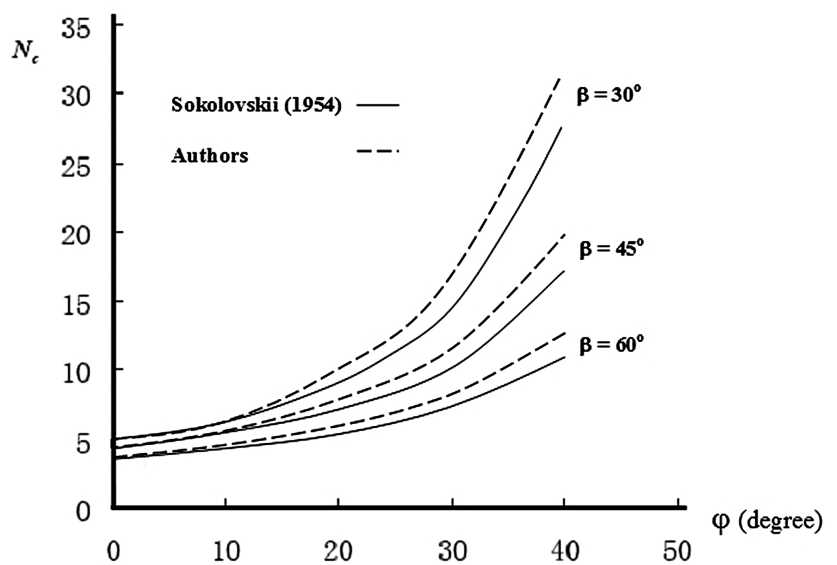

Figure 4. Comparison of $N_{\mathrm{c}}$ values between Sokolovskii method and authors' method.

the safety factor $k$ is increased as the $L / B$ ratios decreased gradually, which is a typical illustration of the importance of three-dimensional effects. When $L / B=1.0$, the failure surface from SRM is still a basically two-dimensional mechanism which is illustrated in Fig. 5, and the factor of safety from SRM is only 1.71 which is far from 2.084 from the present 3-D failure mechanism (as shown in Fig. 1). Unless the loading is large enough, only a 2-D failure mechanism will appear in 3-D SRM which is not realistic, and this is the limitation of the SRM, and the present formulation is better than the SRM in this respect. It is found that when $L / B$ ratio is great so that the failure mechanism is approaching a two-dimensional failure, the results from Eq. (25) is virtually the same as the results from three-dimensional SRM. When $L / B$ ratio is small, there are however more significant differences between the present failure mechanism and the SRM. The shear strain contour at the ultimate state was shown in Fig. 5. There is shear strain concentration, i.e. a shear band from the top to the toe of the slope.

\section{$7 \quad$ Verification by laboratory model tests}

A laboratory test complying exactly with the present problem as shown in Fig. 6 has been performed for the verification of the proposed method. A hydraulic jack applies a local load on top of a $0.8 \mathrm{~m}$ high $65^{\circ}$ inclined slope. The soil used for the model slope is classified as highly permeable poorly graded river sand. The unit weight and the relative density are $\gamma=15.75 \mathrm{kN} \mathrm{m}^{-3}$ and 0.55 , the relative density is defined as the ratio of (actual density-loosest density) against (highest density-loosest density) which is a dimensionless index for soil. Shear strength parameters $\left(c^{\prime}=7 \mathrm{kPa}\right.$ and $\left.\phi^{\prime}=35^{\circ}\right)$ of the soil was determined by means of consolidated drained triaxial test. The depth, breadth and height of the soil tank are $1.5,1.85$ and $1.2 \mathrm{~m}$ respectively. The soil is compacted by an electric compactor with a $0.2 \mathrm{~m} \times 0.2 \mathrm{~m}$ wooden end plate.

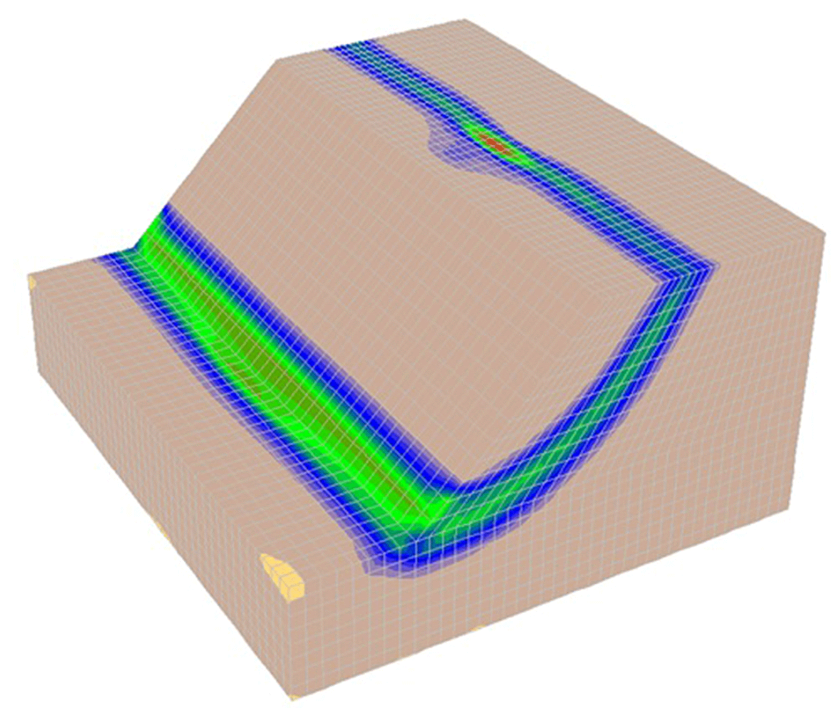

Figure 5. Failure mechanism for $\mathrm{L} / \mathrm{B}=1.0$ by $\mathrm{SRM}$ (shear strain distribution).

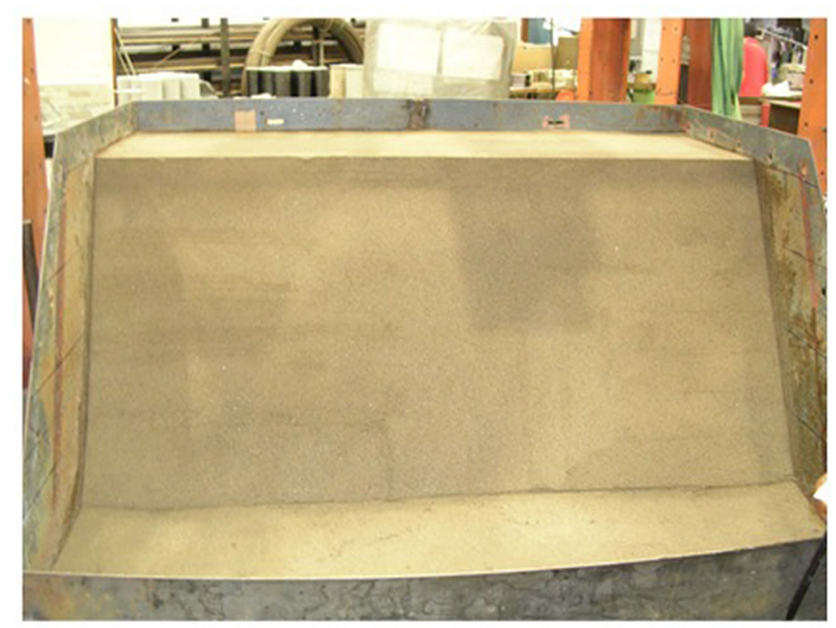

Figure 6. Basic setup of the laboratory test.

Five linear variable differential transducers (LVDTs) are set up to measure the displacement of soil at different locations; the upper right (RHS), upper left (LHS), lower right (RHS) and lower left (LHS) are shown in Fig. 7, and the displacements at different vertical loads are monitored up to failure as shown in 8 . The two pairs of transducers on the slope surface are placed symmetrically with a horizontal spacing of $300 \mathrm{~mm}$. The first and second pairs of transducers are placed at vertical distances of $150 \mathrm{~mm}$ and $450 \mathrm{~mm}$ from the top of the slope, respectively.

The vertical displacement controlled hydraulic jack exerts uniform distributed pressure on a $10 \mathrm{~mm}$ thick steel bearing plate with size $B=0.3 \mathrm{~m}$ and $L=0.644 \mathrm{~m}$ at $0.13 \mathrm{~m}$ away from the crest of the model $(b=0.13 \mathrm{~m})$ until an ultimate load of $35 \mathrm{kN}$ is attained at an displacement of about $6 \mathrm{~mm}$ 
Table 1. Safety factors and geometric parameters (Example 1 and geometry of failure mass) for $q=100 \mathrm{kPa}$.

\begin{tabular}{ccccccccc|c}
\hline$k$ & $\zeta_{\mathrm{cr}}\left(^{\circ}\right)$ & $\xi_{\mathrm{cr}}\left(^{\circ}\right)$ & $\eta_{\mathrm{cr}}\left(^{\circ}\right)$ & $h(m)$ & $c c^{\prime}(m)$ & $g g^{\prime}(m)$ & $i i^{\prime}(m)$ & $L / B$ & $k$ from SRM \\
\hline 1.120 & 69.0 & 68.3 & 94.75 & 6.00 & 0.88 & 3.51 & 0.21 & $\infty$ & 1.19 \\
1.278 & 67.8 & 67.1 & 97.75 & 6.00 & 0.74 & 3.08 & 0.18 & 10 & 1.26 \\
1.311 & 67.3 & 67.0 & 98.25 & 6.00 & 0.72 & 3.01 & 0.17 & 8 & 1.30 \\
1.368 & 67.0 & 66.8 & 99.25 & 6.00 & 0.67 & 2.88 & 0.16 & 6 & 1.33 \\
1.466 & 64.6 & 64.3 & 97.75 & 4.97 & 0.57 & 2.30 & 0.16 & 4 & 1.41 \\
1.706 & 60.8 & 60.5 & 95.00 & 3.72 & 0.43 & 1.57 & 0.15 & 2 & 1.60 \\
2.080 & 57.0 & 56.8 & 92.00 & 2.83 & 0.32 & 1.05 & 0.14 & 1 & 1.71 \\
\hline
\end{tabular}
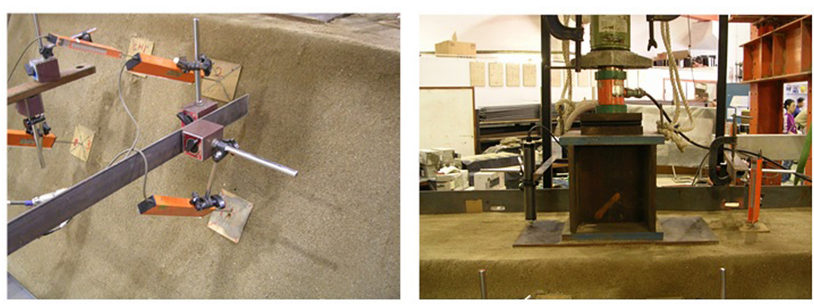

Figure 7. LVDT at top and sloping face of the model test.

as shown in Fig. 8. As a result, the ultimate bearing capacity of the slope under the current soil properties, geometrical conditions and boundary conditions is $181.2 \mathrm{kPa}$, which results in a factor safety 1.021 with the present method. This value is very close to 1.0 , which demonstrates that the result is reasonable. For the slope surface, the corresponding displacement at the maximum pressure is about 2 and $1 \mathrm{~mm}$ at top and bottom of the slope respectively. Beyond the peak load, the applied load decreases with the increasing jack displacement. It is clear that the displacements of the slope are basically symmetrical. The failure surface of the present test is shown in Figs. 9 and 10, and the sectional view at the middle of the failure mass is shown in Fig. 11. In Fig. 8, after the maximum load is achieved, the load will decrease with increasing displacement. At this stage, the local triangular failure zone is fully developed, while the failure zones at the two ends of the plate are not clearly formed. When the applied load has decreased down to about $25 \mathrm{kN}$, the load maintained constant for a while and the failure zones at the two ends are becoming visually clear. When the displacements are further increased, the applied load decreases further, and the failure zone propagate towards the slope surface until the failure surface as shown in Fig. 10 is obtained. This three-dimensional failure mechanism as measured from the model test is basically similar to that as given in the semi-analytical approach, and the prediction of the factor of safety from the present theory is also satisfactory.

For this test, there are several interesting phenomena worth discussing. The failure profile and cracks are firstly initiated beneath the footing as shown in Fig. 9, which is a typical bearing capacity/slope stability failure with a triangular fail-

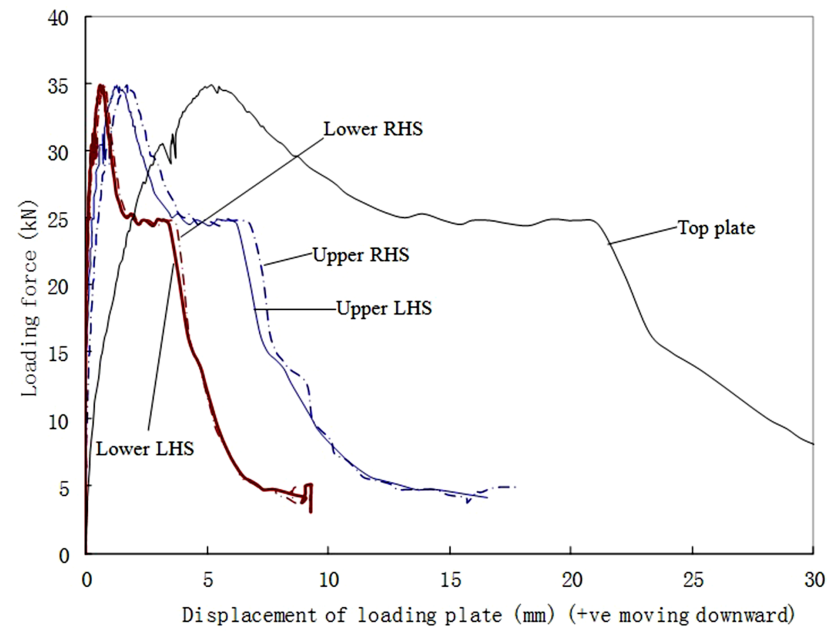

Figure 8. Loading force against the displacement of slope surface.

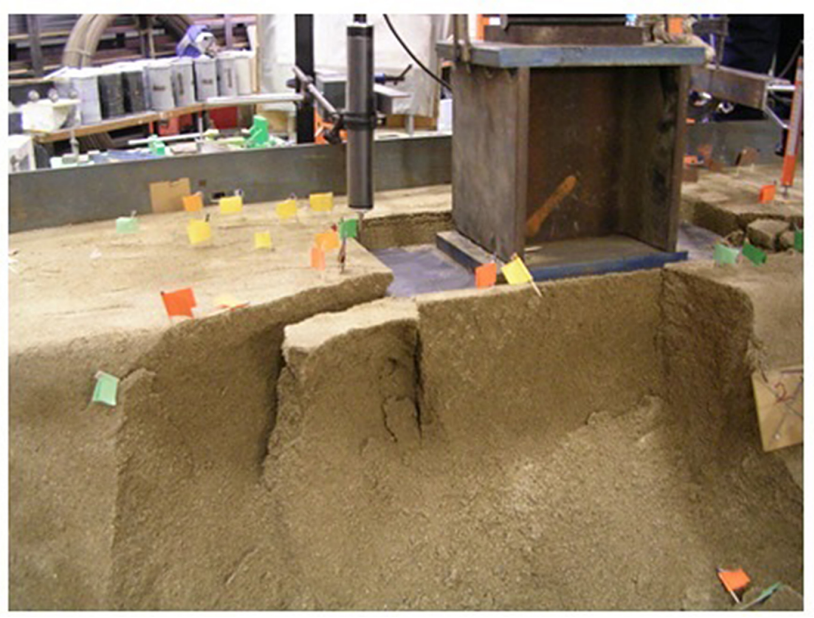

Figure 9. Slope failure beneath bearing plate.

ure zone noted clearly in Fig. 11. This can also be observed from the upper part of the failure profile as shown in Figs. 9 and 10. $\zeta, \varepsilon$ and $\eta$ are obtained as $68,67.5$ and $83.8^{\circ}$ from the critical factor of safety as given by Eq. (25). As the load increased, the failure zone extended and propagated towards the toe of the slope, and the final failure surface is shown in 


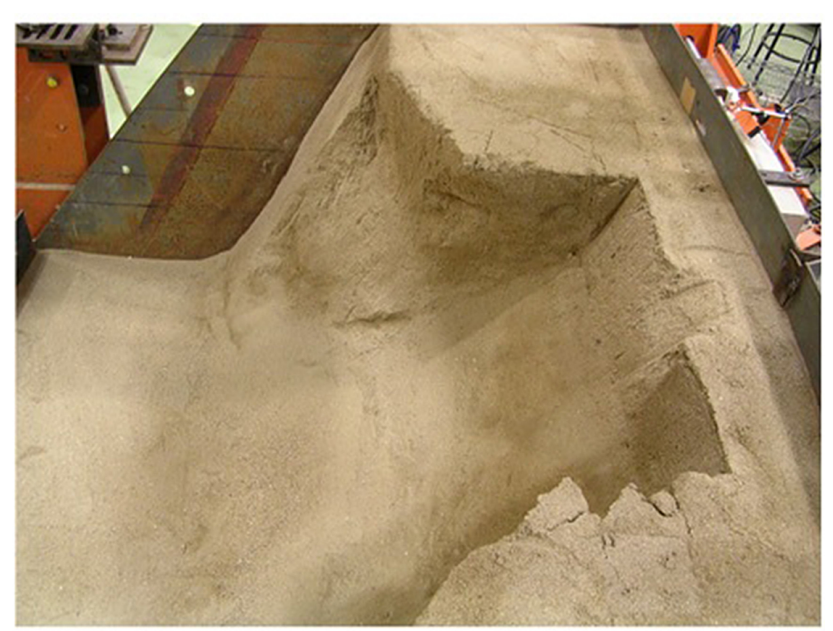

Figure 10. Global three-dimensional slope failure.

Fig. 10. It is observed that the failure mechanism of the physical model test is hence a local triangular failure beneath the bearing plate, and the failure surface propagates towards the slope surface until a failure mechanism is formed. The failure profile matched reasonably well with that as predicted from the present formulation as shown in Fig. 11, and is also in compliance with that as developed by Cheng and Au (2005) using the slip line method. In addition, the prediction of the factor of safety is also close to the back analysis result of the laboratory test. Regarding the difficulty in ensuring complete uniformity for the compaction of the model slope, the small discrepancy between the predicted and measured failure profiles as shown in Fig. 11 can be considered as acceptable.

\section{Discussion and conclusions}

Based on the upper bound theorem of limit analysis, a threedimensional slope stability problem with a patched uniform distributed load on the top surface are investigated. The semianalytical method has demonstrated that the present failure mechanisms are reasonable in predicting the bearing capacity under a patched load on the top surface of slope, which is commonly found for bridge abutment foundation. Furthermore, combined with the traditional safety factor $k$, the allowable load on the top surface of the slope can be obtained by a simple looping method (using Excel or any computer language). The search for the critical factor of safety is just several seconds, which is much faster than that by the SRM which requires about half to 1 day for a complete analysis (and about half a day to set up the computer model for an experienced user), but the results from the proposed analysis is very close to that from the tedious analysis using SRM.

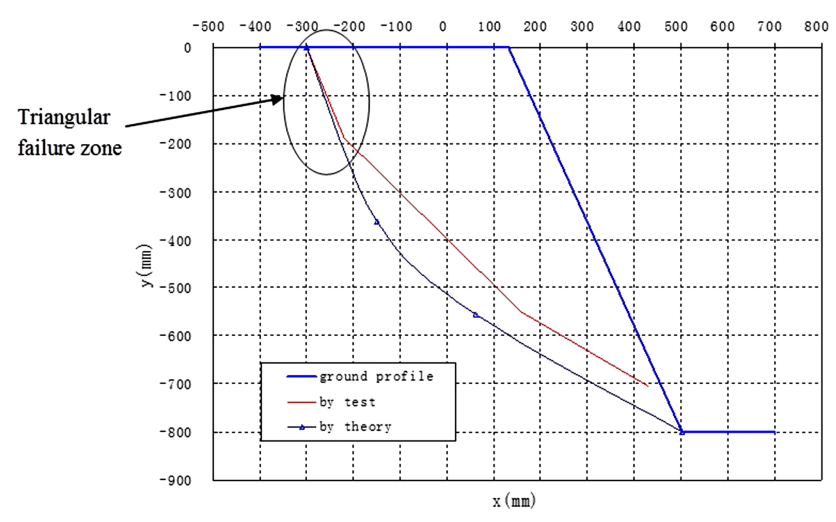

Figure 11. Comparisons between the measure and the predicted failure surface profile at mid-section of failure.

The present formulations are the further extension of previous works, with slightly improved results and more versatile for both surface patch load or buried patch load. Based on the model test and the SRM analysis, it is clear that the present work can be used by engineers for routine analysis and design, and it can provide fast and reliable solution suitable for many practical problems.

The present problem can be viewed as a bearing capacity as well as a slope stability problem, as both types of problem are governed by the same yield and equilibrium requirements. The laboratory test has demonstrated that the present formulation is reasonable, and it will actually reduce to the classical Prandtl mechanism (Prandtl, 1920) when $\beta=0$. The accuracy and suitability of the present formulation are hence also justified from theoretical point of view. 


\section{Appendix A: Geometrical relations}

\section{A1 Three-dimensional slope failure of a slope with patched load on the top surface $(D=0 \mathrm{~m})$}

\section{A1.1 Along footing length $L$}

If the coordinate of point $b$ is $x_{b}=0, y_{b}=0, z_{b}=0$, the corresponding coordinate of point $i$ is $x_{i}=b, y_{i}=0, z_{i}=0$, coordinate of point $d$ is $x_{d}=b d \cos \eta, y_{d}=0, z_{d}=b d \sin \eta$. Since $d g$ is a straight line, to obtain the values $x_{g}$ and $z_{g}$, the following geometric relationships are established and used:

$\frac{z_{g}-z_{d}}{x_{g}-x_{d}}=\tan \left(\varphi+\eta-90^{\circ}\right)$, and $\frac{z_{g}-z_{i}}{x_{g}-x_{i}}=\tan \beta$

Based on the Eq. (A1), $x_{g}$ and $z_{g}$ are expressed as

$$
\begin{aligned}
x_{g}= & \frac{b \tan \beta+z_{d}-x_{d} \tan \left(\varphi+\eta-90^{\circ}\right)}{\tan \beta-\tan \left(\varphi+\eta-90^{\circ}\right)}, \\
& \text { and } z_{g}=\left(x_{g}-b\right) \tan \beta,
\end{aligned}
$$

and $d g$ in Eq. (5) is obtained as

$d g=\sqrt{\left(x_{g}-x_{d}\right)^{2}+\left(z_{g}-z_{d}\right)^{2}}$.

The geometry for wedges $b d g$ and $b i g$ are given by

$S_{b d g}=\frac{1}{2} b d \cdot d g \cos \varphi$,

$S_{b i g}=\frac{1}{2} b i \cdot g i \sin \beta$,

$b i=b$, and $g i=\sqrt{\left(x_{g}-x_{i}\right)^{2}+\left(z_{g}-z_{i}\right)^{2}}$.

\section{A1.2 End failure zone 1}

$a b=B, S_{a b c}=\frac{1}{2} a b \cdot a c \sin \zeta W_{a b c-c^{\prime}}=\frac{\gamma}{3} S_{a b c} \cdot c c^{\prime}$

\section{A1.3 End failure zone 2}

As shown in Fig. 1c, $b-c d d^{\prime} c^{\prime}$ is the three-dimensional end radial shear failure zone 2 . If we assume that $c^{\prime} d^{\prime}$ is a spiral and the centre of the spiral $c^{\prime} d^{\prime}$ is at point $b$, a relationship $R=R_{0} \exp (\varepsilon \tan \varphi)$ will exist in which $R_{0}=b c^{\prime}$ and $R=b f^{\prime}$. For triangle $b f f^{\prime}$, the velocity $v$ is normal to both lines $b f$ and $b f^{\prime}$, so we can deduce that the velocity $v$ is vertical to triangle $b f f^{\prime}$ and line $f f^{\prime}$. In order to ensure kinematically compatible velocity yield for the soil mass of the end radial shear failure zone 2 , for small unit $b-f k k^{\prime} f^{\prime}$, the horizontal angle between $v=v_{0} \exp (\theta \tan \varphi)$ and line $f^{\prime} k^{\prime}$ should be equal to $\phi$. It should be pointed out that $c c^{\prime} d^{\prime} d$ is normal to the plane $a b c$, and the corresponding relationship between $R d \varepsilon$ and $r d \theta$ is expressed as

$r d \theta / \cos \varphi=R d \varepsilon$, in which $r=r_{0} \exp (\theta \tan \varphi), R=R_{0} \exp (\varepsilon \tan \varphi)$, and $r_{0}=$ $R_{0} \cos \varphi$. Integrating both sides of Eq. (A6) yield

$\theta=\varepsilon, \Theta=\varepsilon_{H}$,

in which $\Theta$ is an angle between $b c$ and $b d$, and $\varepsilon_{H}$ is the angle between line $b c^{\prime}$ and line $b d^{\prime}$.

a. Velocity discontinuity curve plane $b c^{\prime} d^{\prime}$

Velocity discontinuity plane area $b f k^{\prime}$ is expressed as

$S_{b f^{\prime} k^{\prime}}=\frac{1}{2} R^{2} \sin d \varepsilon=\frac{1}{2} R^{2} d \varepsilon$.

b. Velocity discontinuity plane $c c^{\prime} d^{\prime} d$

Line $f f^{\prime}$ is normal to line $b f$, therefore $f f^{\prime}$ is expressed as

$$
f f^{\prime}=\left(R^{2}-r^{2}\right)^{\frac{1}{2}}=r_{0} \tan \varphi \exp (\theta \tan \varphi)
$$

Unit area of $f f^{\prime} k^{\prime} k$ is expressed as

$$
. S_{f f^{\prime} k^{\prime} k}=f f^{\prime} \cdot R d \varepsilon=r_{0} R_{0} \tan \varphi \exp (2 \theta \tan \varphi) d \theta
$$

c. Radial shear zone $b-c c^{\prime} d^{\prime} d$

Area of triangle $b f f^{\prime}$ is expressed as

$$
S_{b f f^{\prime}}=\frac{1}{2} b f \cdot f f^{\prime}=\frac{1}{2} r_{0}^{2} \tan \varphi \exp (2 \theta \tan \varphi) .
$$

in which $b f=r_{0} \exp (\theta \tan \varphi)$.

d. Weight of the radial zone $b-c c^{\prime} d^{\prime} d(0 \leq \theta \leq \Theta)$

The weight of the unit wedge $b-f f^{\prime} k k^{\prime}$ is obtained as

$$
\begin{gathered}
W_{b-f f^{\prime} k^{\prime} k}=\frac{\gamma}{3} S_{f f^{\prime} k^{\prime} k} \cdot b f \cos \varphi=\frac{\gamma}{3} r_{0}^{2} R_{0} \\
\sin \varphi \exp (3 \theta \tan \varphi) d \theta .
\end{gathered}
$$

\section{A1.4 End failure zone 3}

As shown in Fig. 1c, line $d g$ is parallel to line $d^{\prime} g$ ". In order to ensure that the kinematical velocity of soil mass of the end failure zone 3 is compatible, the angle between line $d^{\prime} g^{\prime}$ and line $d^{\prime} g^{\prime \prime}$ should be equal to $\varphi$. It should be mentioned that straight lines $g g^{\prime \prime} g^{\prime}$ and $i i^{\prime}$ are both in the slope surface, both triangle $b d^{\prime} g^{\prime}$ and triangle $b g^{\prime} i^{\prime}$ are located on the same velocity discontinuity plane $b d^{\prime} g^{\prime} i^{\prime} b$, and triangle $b i i^{\prime}$ is located in the top surface of the slope. 
a. Velocity discontinuity plane $d d^{\prime} g^{\prime} g$.

The area of velocity discontinuity plane $d d^{\prime} g^{\prime} g$ is expressed as

$S_{d d^{\prime} g^{\prime} g}=d d^{\prime} \cdot d g+\frac{1}{2} d g \cdot d g \cdot \tan \varphi$

in which $d d^{\prime}=r_{0} \tan \varphi \exp (\Theta \tan \varphi)$.

b. Velocity discontinuity plane $b d^{\prime} g^{\prime} i^{\prime}$

As shown in Fig. 1c, coordinate of point $d^{\prime}$ is $x_{d^{\prime}}=$ $x_{d}, y_{d^{\prime}}=d d^{\prime}, z_{d^{\prime}}=z_{d}$, coordinate of point $g^{\prime}$ is $x_{g^{\prime}}=$ $x_{g}, y_{g^{\prime}}=d d^{\prime}+d g \cdot \tan \varphi, z_{g^{\prime}}=z_{g}$, and coordinate of $i^{\prime}$ is $x_{i^{\prime}}=x_{i}, y_{i^{\prime}}=y_{i}, z_{i^{\prime}}=z_{i}$. The equation of the plane formed by points $b, d^{\prime}$ and $g^{\prime}$ is written as

$\left|\begin{array}{ccc}x-x_{b} & y-y_{b} & z-z_{b} \\ x_{d^{\prime}}-x_{b} & y_{d^{\prime}}-y_{b} & z_{d^{\prime}}-z_{b} \\ x_{g^{\prime}}-x_{b} & y_{g^{\prime}}-y_{b} & z_{g^{\prime}}-z_{b}\end{array}\right|=0$.

Point $i^{\prime}$ should be on the velocity discontinuity plane $b d^{\prime} g^{\prime} i^{\prime}$, so $x, y, z$ are replaced by $x_{i^{\prime}}, y_{i^{\prime}}, z_{i^{\prime}}$ in the equation $(\mathrm{n})$, then $y_{i^{\prime}}$ is given as

$y_{i^{\prime}}=b \frac{z_{d^{\prime}} \cdot y_{g^{\prime}}-y_{d^{\prime}} \cdot z_{g^{\prime}}}{z_{d^{\prime}} \cdot x_{g^{\prime}}-x_{d^{\prime}} \cdot z_{g^{\prime}}}$.

The area of the velocity discontinuity plane $b d^{\prime} g^{\prime}$ is expressed as

$S_{b d^{\prime} g^{\prime}}=$

$\sqrt{\frac{1}{16}\left(b d^{\prime}+d^{\prime} g^{\prime}+b g^{\prime}\right)\left(b d^{\prime}+d^{\prime} g^{\prime}-b g^{\prime}\right)\left(b d^{\prime}-d^{\prime} g^{\prime}+b g^{\prime}\right)\left(-b d^{\prime}+d^{\prime} g^{\prime}+b g^{\prime}\right)}$,

in which corresponding $b d^{\prime}=$ $R_{0} \exp (\Theta \tan \varphi), d^{\prime} g^{\prime}=d g / \cos \varphi \quad$ and $\quad b g^{\prime}=$ $\sqrt{\left(x_{b}-x_{g^{\prime}}\right)^{2}+\left(y_{b}-y_{g^{\prime}}\right)^{2}+\left(z_{b}-z_{g^{\prime}}\right)^{2}}$.

The area of the velocity discontinuity plane $b g^{\prime} i^{\prime}$ is written as

$S_{b g^{\prime} i^{\prime}}=$

$\sqrt{\frac{1}{16}\left(b g^{\prime}+b i^{\prime}+g^{\prime} i^{\prime}\right)\left(b g^{\prime}+b i^{\prime}-g^{\prime} i^{\prime}\right)\left(b g^{\prime}-b i^{\prime}+g^{\prime} i^{\prime}\right)\left(-b g^{\prime}+b i^{\prime}+g^{\prime} i^{\prime}\right)}$

where $g^{\prime} i^{\prime}=\sqrt{\left(x_{i^{\prime}}-x_{g^{\prime}}\right)^{2}+\left(y_{i^{\prime}}-y_{g^{\prime}}\right)^{2}+\left(z_{i^{\prime}}-z_{g^{\prime}}\right)^{2}}$, and $b i^{\prime}=\sqrt{b^{2}+y_{i^{\prime}}^{2}}$.

\section{A2 Three-dimensional slope failure with an embedded patched load $(D>0 \mathrm{~m})$}

\section{A2.1 Along footing length $L$}

As shown in Fig. $2 \mathrm{a}$, if the coordinate of point $b$ is $x_{b}=$ $0, y_{b}=0, z_{b}=0$, the corresponding coordinate of point $i$ will be $x_{i}=b, y_{i}=0, z_{i}=-D$, coordinate of point $d$ is $x_{d}=b d \cos \eta, y_{d}=0, z_{d}=b d \sin \eta$, coordinate of point $h$ is $x_{h}=0, y_{h}=0, z_{h}=-D$. The values of $x_{g}$ and $z_{g}$ are obtained through the following geometric relationships:

$\frac{z_{g}-z_{d}}{x_{g}-x_{d}}=\tan \left(\varphi+\eta-90^{\circ}\right)$, and $\frac{z_{g}-z_{i}}{x_{g}-x_{i}}=\tan \beta$.

Based on Eq. (A18), $x_{g}$ and $z_{g}$ are expressed as

$$
\begin{aligned}
& x_{g}=\frac{b \tan \beta+D+z_{d}-x_{d} \tan \left(\varphi+\eta-90^{\circ}\right)}{\tan \beta-\tan \left(\varphi+\eta-90^{\circ}\right)}, \\
& z_{g}=\left(x_{g}-b\right) \tan \beta-D .
\end{aligned}
$$

And $d g$ in Eq. (A19) is obtained as

$d g=\sqrt{\left(x_{g}-x_{d}\right)^{2}+\left(z_{g}-z_{d}\right)^{2}}$.

\section{A2.2 Wedge bdgih}

Area of bdgih is obtained as

$S_{b d g i h}=S_{b d g}+S_{b i g}+S_{b h i}$,

in which

$S_{b d g}=\frac{1}{2} b d \cdot d g \cos \varphi$

$S_{b i g}=$

$\sqrt{\frac{1}{16}(b g+g i+b i)(b g+g i-b i)(b g-g i+b i)(-b g+g i+b i)}$,

where $\quad b g=\sqrt{\left(x_{b}-x_{g}\right)^{2}+\left(z_{b}-z_{g}\right)^{2}}, \quad g i=$ $\sqrt{\left(x_{g}-x_{i}\right)^{2}+\left(z_{g}-z_{i}\right)^{2}}$ and $b i=\sqrt{\left(x_{b}-x_{i}\right)^{2}+\left(z_{b}-z_{i}\right)^{2}}$.

\section{A2.3 Two failure ends of the buried load}

As shown in Fig. 2b, the coordinates of point $d^{\prime}, g^{\prime}$ and $i^{\prime}$ are similar to the case of $D=0$. Point $i^{\prime}$ should be on the velocity discontinuity plane $b d^{\prime} g^{\prime} i^{\prime}$, so $x, y, z$ are replaced by $x_{i^{\prime}}, y_{i^{\prime}}, z_{i^{\prime}}$ in the Eq. (A15), then $y_{i^{\prime}}$ is

$y_{i^{\prime}}=b \frac{z_{d^{\prime}} \cdot y_{g^{\prime}}-y_{d^{\prime}} \cdot z_{g^{\prime}}}{z_{d^{\prime}} \cdot x_{g^{\prime}}-x_{d^{\prime}} \cdot z_{g^{\prime}}}+D \frac{x_{d^{\prime}} \cdot y_{g^{\prime}}-y_{d^{\prime}} \cdot x_{g^{\prime}}}{z_{d^{\prime}} \cdot x_{g^{\prime}}-x_{d^{\prime}} \cdot z_{g^{\prime}}}$

wedges $b-d d^{\prime} g^{\prime} g, b-i i^{\prime} g^{\prime} g$ and $b-h i i^{\prime}$. 


\section{A2.4 Weight of the wedges $b-d d^{\prime} g^{\prime} g, b-i i^{\prime} g^{\prime} g$ and b-hii'}

Weight of the wedge $b-d d^{\prime} g^{\prime} g$ is expressed as

$W_{b-d d^{\prime} g^{\prime} g}=\frac{\gamma}{3} S_{d d^{\prime} g^{\prime} g} \cdot b d \cos \varphi$

. Area of the slope surface $i i^{\prime} g^{\prime} g$ is expressed as

$S_{i i^{\prime} g^{\prime} g}=\frac{1}{2}\left(i i^{\prime}+g g^{\prime}\right) \cdot g i$.

in which $i i^{\prime}=y_{i^{\prime}}, \quad g g^{\prime}=d d^{\prime}+d g \tan \varphi, \quad$ and $\quad g i=$ $\sqrt{\left(x_{g}-x_{i}\right)^{2}+\left(z_{g}-z_{i}\right)^{2}}$. Weight of the wedge $b-i i^{\prime} g^{\prime} g$ is given as

$W_{b-i i^{\prime} g^{\prime} g}=\frac{\gamma}{3} \cdot S_{i i^{\prime} g^{\prime} g} \cdot(b \cdot \sin \beta+D \cdot \cos \beta)$.

Area of triangle $h i i^{\prime}$ is given as

$S_{h i i^{\prime}}=\frac{1}{2} b \cdot y_{i^{\prime}}$.

Weight of the wedge $b-h i i^{\prime}$ is written as

$W_{b-h i i^{\prime} i}=\frac{\gamma}{3} \cdot S_{h i i^{\prime}} \cdot D$.

Table A1. Notation.

\begin{tabular}{|c|c|}
\hline$A$ & Discontinuity area dominant $\left(\mathrm{m}^{2}\right)$ \\
\hline$B$ & Width of the footing $(\mathrm{m})$ \\
\hline$b$ & $\begin{array}{l}\text { Distance away from the crest of slope for the } \\
\text { patched load (m) }\end{array}$ \\
\hline$c_{\mathrm{s}}$ & Soil cohesion strength $\left(\mathrm{kN} \mathrm{m}^{-2}\right)$ \\
\hline$c$ & Mobilized cohesive strength $\left(\mathrm{kN} \mathrm{m}^{-2}\right)$ \\
\hline$D$ & Embedment depth (m) \\
\hline$H$ & Height of slope (m) \\
\hline$k$ & Safety factor (dimensionless) \\
\hline$L$ & Load length (m) \\
\hline$N_{\mathrm{c}}$ & Bearing capacity factor (dimensionless) \\
\hline$q$ & External pressure $\left(\mathrm{kN} \mathrm{m}^{-2}\right)$ \\
\hline$q_{\mathrm{u}}$ & Ultimate bearing pressure $\left(\mathrm{kN} \mathrm{m}^{-2}\right)$ \\
\hline$V$ & Volume domain $\left(\mathrm{m}^{3}\right)$ \\
\hline S & Boundary area domain $\left(\mathrm{m}^{2}\right)$ \\
\hline$W_{\mathrm{R}}^{\bullet}$ & Resistance rate of work done $(\mathrm{kN} \mathrm{m})$ \\
\hline$W_{\mathrm{D}} \bullet$ & Driving rate work done $(\mathrm{kN} \mathrm{m})$ \\
\hline$\varphi$ & Internal friction angle (degree) \\
\hline$\varphi_{e}$ & Mobilized internal friction angle (degree) \\
\hline$f\left(\sigma_{i j}\right)$ & Yield function (dimensionless) \\
\hline$\beta$ & Slope angle (degree) \\
\hline$\varepsilon_{i j}{ }^{\circ}$ & Strain rate tensors $\left(\mathrm{s}^{-1}\right)$ \\
\hline$\lambda$ & Non-negative scalar function (dimensionless) \\
\hline$\eta, \xi, \theta, \varepsilon, \Theta$ & Angle of the wedges as shown in Fig. 1 (degree) \\
\hline$\eta_{\mathrm{cr}}, \xi_{\mathrm{cr}}$ & $\begin{array}{l}\text { Angle of the wedge at failure as shown } \\
\text { in Fig. } 1 \text { (degree) }\end{array}$ \\
\hline$\sigma_{i j}$ & Stress tensors $\left(\mathrm{kN} \mathrm{m}^{-2}\right)$ \\
\hline$t_{i}$ & Traction over the velocity jumps $[v]_{i}\left(\mathrm{kN} \mathrm{m}^{-2}\right)$ \\
\hline$[v]_{i}$ & Velocity jumps (m) \\
\hline$\gamma_{i}$ & Unit weight $\left(\mathrm{kN} \mathrm{m}^{-3}\right)$ \\
\hline$v_{0}, v_{3}$ & $\begin{array}{l}\text { Velocity along the failure profile as shown in } \\
\text { Fig. } 1(\mathrm{~m})\end{array}$ \\
\hline$v_{1}$ & Velocity of the patched load (m) \\
\hline$x, y, z$ & $\begin{array}{l}\text { Coordinates of the slope surface or the failure } \\
\text { profile }(\mathrm{m})\end{array}$ \\
\hline
\end{tabular}


Acknowledgements. The authors would like to thanks to the support from The Hong Kong Polytechnic University through the account ZVCR and Research Grant Council project PolyU 5128/13E.

Edited by: T. Glade

Reviewed by: C. Zangerl and one anonymous referee

\section{References}

Azzouz, A. S. and Baligh, M. M.: Loaded areas on cohesive slopes, J. Geotech. Eng.-ASCE, 109, 709-729, 1983.

Bagge, G.:Tension cracks in saturated clay cutting, Proc. 11. th. Int. Conf. on. Soil Mechanics and Foundation Engineering, San Francisco, 393-395, 12-16 August, 1985.

Baker, R.: Tensile strength, tensile cracks, and stability of slopes, Soils Found., 21, 1-17, 1981.

Bishop, A. W.: The use of the slip circle in stability analysis of slopes, Geotechnique, 5, 7-17, 1955.

Chen, J., Yin, J. H., and Lee, C. F.: Upper bound limit analysis of slope stability using rigid elements and nonlinear programming, Can. Geotech. J., 40, 742-752, 2003.

Chen, R. H. and Chameau, J. L.: Three dimensional limit equilibrium analysis of slopes, Geotechnique, 32, 31-40, 1982.

Chen, W. F.: Limit analysis and soil plasticity, 47-106, Elsevier Scientific Publishing Company, USA, 1975.

Chen, W. F. and Liu, X. L.: Limit analysis in soil mechanics, 46 and 437-469, Elsevier Scientific Publishing Company, USA, 1990.

Chen, Z., Wang, X., Haberfield, C., Yin, J. H., and Wang, Y.: A three dimensional slope stability analysis method using the upper bound theorem, Part 1: Theory and methods, Int. J. Rock Mech. Min., 38, 369-378, 2001a.

Chen, Z., Wang, J., Wang, Y., Yin, J. H., and Haberfield, C.: A three dimensional slope stability analysis method using the upper bound theorem, Part 2: Numerical approaches, applications and extensions, Int. J. Rock Mech. Min., 38, 379-397, 2001 b.

Cheng, Y. M. and Au, S. K.: Slip line solution of bearing capacity problems with inclined ground, Can. Geotech. J., 42, 1232-1241, 2005.

Cheng, Y. M. and Lau, C. K.: Slope Stability Analysis and Stabilization: New Methods and Insight, 2nd Edn., 54, CRC Press, Taylor \& Fracis Group, USA, 2013.

Cheng, Y. M. and Yip, C. J.: "Three-dimensional Asymmetrical Slope Stability Analysis - Extension of Bishop's and Janbu's Techniques", J. Geotech. Geoenviron., 133, 1544-1555, 2007.

Cheng, Y. M., Lansivarra, T., and Wei, W. B.: Two-dimensional Slope Stability Analysis by Limit Equilibrium and Strength Reduction Methods, Comput. Geotech., 34, 137-150, 2007.
Cheng, Y. M., Lansivaara, T., Baker, R., and Li, N.: The use of internal and external variables and extremum principle in limit equilibrium formulations with application to bearing capacity and slope stability problems, Soils Found., 53, 130-143, 2013 a.

Cheng, Y. M., Au, S. K., Pearson, A. M., and Li, N.: An innovative Geonail System for soft ground stabilization, Soils Found., 53, 282-298, 2013b.

Farzaneh, O. and Askari, F.: Three-dimensional analysis of nonhomogeneous slopes, J. Geotech. Geoenviron.-Eng., 129, 137-145, 2003.

Giger, M. W. and Krizek, R. J.: Stability analysis of vertical cut with variable corner angle, Soils Found., 15, 63-71, 1975.

Hovland, H. J.: Three dimensional slope stability analysis method, J. Geotech. Eng.-ASCE, 103, 971-986, 1977.

Hungr, O.: An extension of Bishop's simplified method of slope stability analysis to three dimensions, Geotechnique, 37, 113117, 1987.

Huang, C. C. and Tsai, C. C.: New method for 3D and asymmetrical slope stability analysis, J. Geotech. Geoenviron., 126, 917-927, 2000.

Huang, C. C. and Tsai, C. C.: General method for three-dimensional slope stability analysis, J. Geotech. Geoenviron., 128, 836-848, 2002.

Janbu, N.: Slope stability computations, in: Embankment-Dam Engineering, edited by: Hirschfield, R. C. and Poulos, S. J., John Wiley, 47-86, 1973.

Lam, L. and Fredlund, D. G.: A general limit equilibrium model for three-dimensional slope stability analysis, Can. Geotech. J., 30, 905-919, 1993.

Li, N. and Cheng, Y. M.: Laboratory and 3-D distinct element analysis of the failure mechanism of a slope under external surcharge, Nat. Hazards Earth Syst. Sci., 15, 35-43, doi:10.5194/nhess-1535-2015, 2015.

Michalowski, R. L.: Three dimensional analysis of locally loaded slopes. Geotechnique, 39, 27-38, 1989.

Morgenstern, N. R. and Price, V. E.: The analysis of stability of general slip surfaces, Geotechnique, 15, 79-93, 1965.

Prandtl, L.: Über die Härte Plastischer Körper. Göttingen Nachr., Mathematisch Physikalische Klasse, 12, 74-85, 1920.

Sokolovskii, V. V.: Statics of Soil Media (translated by D. H. Jones and A. N. Scholfield), Butterworths Scientific, London, 1960.

Spencer, E.: A method of analysis of the stability of embankments assuming parallel inter-slice forces, Geotechnique, 17, 11-26, 1967.

Wei, W. B., Cheng, Y. M., and Li, L.: Three-dimensional slope failure by strength reduction and limit equilibrium methods, Comput. Geotech., 36, 70-80, 2009. 